\title{
Metrology: A New Open Access Journal with a Broad Scope and an Exciting Mission
}

\author{
Han Haitjema
}

Citation: Haitjema, H. Metrology: A New Open Access Journal with a Broad Scope and an Exciting Mission. Metrology 2021, 1, 74-75. https:// doi.org/10.3390/metrology1010005

Received: 27 August 2021

Accepted: 31 August 2021

Published: 3 September 2021

Publisher's Note: MDPI stays neutral with regard to jurisdictional claims in published maps and institutional affiliations.

Copyright: (C) 2021 by the author. Licensee MDPI, Basel, Switzerland. This article is an open access article distributed under the terms and conditions of the Creative Commons Attribution (CC BY) license (https:// creativecommons.org/licenses/by/ $4.0 /)$.
Manufacturing Metrology Section, Manufacturing Processes and Systems (MaPS), Department of Mechanical Engineering, KU Leuven, 3001 Leuven, Belgium; han.haitjema@kuleuven.be

It is with sincere pleasure that we welcome you to the inaugural issue of Metrology. Metrology is dedicated to the dissemination of rigorously peer-reviewed publications on metrology, including all its allied topics.

The launch of this journal is truly exciting. It brings much promise and much opportunity for making and disseminating contributions that advance metrology in all of its guises, as well as their connections and interactions with many other areas, including but not limited to uncertainty evaluation, error compensation, digital twins, artificial intelligence and machine learning. The journal aims to publish methods and technologies that lie at the forefront of knowledge, and that advance our knowledge in fundamental ways.

The name Metrology hints that the journal's focus is on the formal definition of metrology: "metrology is the science of measurement and its application" (International Vocabulary of Metrology, 2012), where it is noted that metrology includes all theoretical and practical aspects of measurement, whatever the measurement uncertainty and field of application may be. This broad scope does not imply that any modeled or physical measurement can be published in Metrology: rather, the journal is concerned with innovative concepts, new perspectives and illustrations of applications from which other readers can benefit; operating beyond the traditional boundaries between metrology fields. Basic metrological concepts such as uncertainty evaluation and traceability to the seven base units of the International System of Units are the natural background for all contributions.

As an open-access journal, Metrology aims to provide high visibility and a timely research impact and is committed to rapid publication. The outstanding systems and staff that MDPI have developed over the years facilitate the achievement of the timely and highquality review of submitted articles, and online publication allows rapid dissemination. The journal provides a venue for both specialized and multi-disciplinary research on metrology and its applications.

Metrology publishes full research papers, communications and review articles. There is no restriction on the length of papers and no additional charges for color figures. The journal allows for electronic files to be deposited as Supplementary Materials, whereby details of calculations and experimental procedures can be supplied.

With respect to the scope of the journal, Metrology covers a broad range of areas, such as studies related to the following topics:

- Traceability to SI units of complex measurement systems;

- Uncertainty evaluation;

- Micro- and nanosystems;

- Considerations on the fundamentals of measurement;

- Error separation methods;

- $\quad$ Novel methods inspired by the redefinition of the SI;

- Cyber-physical systems;

- Artificial intelligence, especially its effect on traceability;

- Machine learning for metrology;

- Digital twins; 
- Metrology for sustainable manufacturing;

- Measurement uncertainty in dynamic processes.

We are pleased to have recruited an outstanding and growing editorial board, comprised of highly accomplished experts in metrology. I look forward to working with this distinguished team in the coming years to establish Metrology as a leading journal with a unique and valuable mission.

I also look forward to hearing from you, our readers and authors, and working with you in order to achieve the journal's goals. Together, we can advance fundamental knowledge and develop innovative applications that will make a difference in technology and society.

Funding: This research received no external funding.

Institutional Review Board Statement: Not applicable.

Informed Consent Statement: Not applicable.

Data Availability Statement: Not applicable.

Conflicts of Interest: The author declares no conflict of interest.

\section{Short Biography of Author}

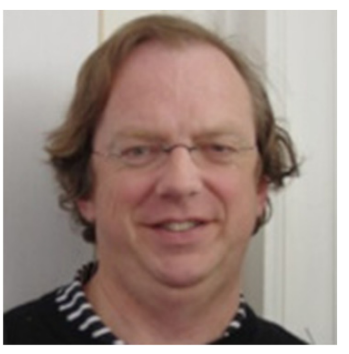

Professor Han Haitjema is currently Professor of Dimensional and Surface Metrology of Complex Products at the Department of Mechanical Engineering, KU Leven, Belgium. Prior to coming to Leuven in mid-2018, he was director of the Mitutoyo Research Center Europe at Best, the Netherlands, where he had settled in 2004 after a career at the Dutch National Metrology institute and the Eindhoven University of Technology since 1989, always in the field of dimensional metrology and precision engineering. He is a Fellow of CIRP, the International Academy for Production Engineering and is on the editorial board of a number of international journals. 